\title{
Utterances to evaluate steps and control attention distinguish operant from respondent thought while thinking out loud*
}

\author{
ERIC KLINGER† \\ University of Minnesota, Morris, Minnesota 56267
}

\begin{abstract}
Ss were instructed to think out loud while engaged in solving manual puzzles, solving logic problems, revery, and quasihypnagogic thought. During the manual puzzle and logic problem activity, they produced significantly more utterances in which they evaluated their previous problem-solving thoughts or acts and in which they indicated that they were controlling their attention than during revery and hypnagogic thought. The findings are interpreted to support the distinction between operant and respondent thought, and they help to characterize the former. They carry implications for theory of thinking, response organization, cognitive development, self-regulation, and thinking dysfunctions as in mental fatigue and psychosis.
\end{abstract}

The research reported here begins with a theory of undirected thought (Klinger, 1971), assumes that the factors that determine the content of undirected thought also operate on directed thought, and seeks to find the properties that must be added to, or transformed from, undirected thought in order to produce directed thinking. The theory divides the content of thought (excluding blank states) into two broad classes, operant and respondent segments. At least four elements of operant thought (operant elements), one phenomenal and three objectifiable, appear to distinguish it from respondent thought: a sense of trying (which may correspond to some sort of hyperenergization of the processes involved in problem-solving), evaluation of success, accommodation of feedback, and control of attention. The results reported below test and confirm the hypothesis that Ss thinking out loud will more often manifest evaluation and control of attention during operant task activity than during activity designed to foster respondent thought.

\section{METHOD}

\section{Subjects}

Male college students were recruited randomly from a student directory and paid (Experiment $1, \mathrm{~N}=24$ ), or recruited from a large course $\mathrm{S}$ pool and unpaid (Experiment 2, $\mathrm{N}=6$ ).

\section{Design and Analysis}

Every $S$ underwent each of four experimental conditions in a Ss by Treatments design. In view of great heterogeneity of

*The research was supported by National Science Foundation Grant GS-1346, which also supported much of the larger theoretical development, and by the Graduate School of the University of Minnesota.

†The author thanks Cheryl Barta, Steven G. Barta, Jane Delage, Ronald O. Hietala, Thomas F. Lehmberg, Mary Martin, Gail Rixen, and Deborah A. Smith for their contributions to the various stages of the research, and to Charles Liberty for help ful comments on an earlier draft of this report. Publication of this paper in the Bulletin is sponsored by Ernest D. Kemble. Requests for reprints should be sent to Eric Klinger, Division of Social Sciences, University of Minnesota, Morris, Minnesota 56267. variance among the treatments and a pronounced correlation between treatment means and variances, the portmanteau test used was Friedman's rank analysis for matched groups. Simple treatment comparisons were tested by use of sign tests in Experiment 1 and by $\mathrm{t}$ tests for correlated data in Experiment 2.

Each condition consisted of $5 \mathrm{~min}$ activity during which Ss were instructed to think out loud. Two conditions required operant thought, and two encouraged respondent thought. During a manual puzzle condition, Ss tried to separate twisted wire pieces (Experiment 1) or to reassemble the pieces of a toy wooden barrel (Experiment 2). In a second condition, Ss tried to think through a verbal logic problem (e.g., "In a certain mythical community, politicians always lie, and nonpoliticians always tell the truth. ... How many of the three natives are politicians?"). During a revery condition, Ss were seated upright in a chair, eyes open, with instructions to let their minds wander. A hypnagogic condition was similar, except that Ss reclined in their chairs with eyes closed, and the condition was preceded by $10 \mathrm{~min}$ of rest in the same chair without talking. During Experiment 1 , every $S$ received the conditions in the order described above. Experiment 2 Ss received them in reverse order. ${ }^{1}$

\section{Procedure}

Ss spent the experiment alone in a cubicle, with all instructions tape recorded and relayed over an intercom. Ss' responses were tape recorded and transcribed for scoring. Instructions first introduced the idea of thinking out loud as a process of verbalizing continuously rather than retrospectively reporting segments of content, a feature emphasized somewhat more strongly in Experiment 2 than in Experiment 1. (The methodological advantages and disadvantages of thinking-out-loud procedures are considered elsewhere: DeGroot, 1965; Klinger, 1971; Newell \& Simon, 1972.) Each condition was then preceded by its own special instructions. Three Experiment 1 Ss failed to verbalize during the first condition (manual puzzle) and were reinstructed.

\section{Scoring}

Two student judges (one for each experiment), who were uninformed concerning the hypotheses, marked those utterances on the transcripts that indicated evaluation and control of attention. Written instructions included examples ("Yep," "Dammit," "Now wait," etc., for evaluation; "Let's see," "Where was 1?", etc., for control of attention) as well as a description of the two thought classes. Interscorer reliabilities comparing the two judges with a third judge, calculated for the 27 manual puzzles protocols, were .82 for evaluation scores and .96 for attention-control scores. 
Table 1

Mean Number of Evaluative and Attention-Control Utterances

\begin{tabular}{|c|c|c|c|c|c|c|}
\hline & \multirow{2}{*}{$\begin{array}{c}\text { Experi- } \\
\text { ment }\end{array}$} & & \multicolumn{4}{|c|}{ Condition } \\
\hline & & & MP & LP & $\mathrm{Re}$ & $\mathrm{Hy}$ \\
\hline \multirow{4}{*}{ Eval } & \multirow{2}{*}{1} & Mean & 2.48 & 2.00 & 0.42 & 0.25 \\
\hline & & SD & 2.31 & 3.15 & 0.77 & 0.61 \\
\hline & \multirow{2}{*}{2} & Mean & 16.50 & 5.83 & 1.50 & 1.17 \\
\hline & & SD & 11.33 & 3.12 & 3.67 & 2.86 \\
\hline \multirow{4}{*}{ At-C } & \multirow{2}{*}{1} & Mean & 2.71 & 3.00 & 0.79 & 0.58 \\
\hline & & SD & 4.44 & 2.78 & 1.06 & 0.93 \\
\hline & \multirow{2}{*}{2} & Mean & 1.17 & 1.50 & 0.00 & 0.17 \\
\hline & & SD & 0.98 & 1.38 & - & 0.41 \\
\hline
\end{tabular}

${ }^{*} R=$ response

\section{RESULTS}

The median numbers of words spoken were 1,428 and 1,235 in Experiments 1 and 2, with ranges from 390 to 3,150 and 1,205 to 1,958 , respectively, and quartile points in Experiment 1 of 846 and 1,704. Thus, the median S spoke about a word per second.

The Friedman ranks analysis found treatment effects - significant in both Experiment $1(p<.001$ for both evaluative and attention-control utterances) and Experiment $2(\mathrm{p}<.01$ for evaluation and $<.05$ for attention control). Both evaluative and attention-control utterances were higher in the two conditions requiring operant activity than in the others (Tables 1 and 2). The proportion of all Ss who produced more scorable utterances in the manual puzzle and logic problem conditions combined than during revery and hypnagogic combined (omitting cases where they are equal) is $27 / 29$ $(p<.0001)$ for evaluative utterances and 24/26 $(\mathrm{p}<.0001)$ for attention-control utterances. Both comparisons are significant for Experiment 1 data alone $(\mathrm{p}<.0001)$, and for Experiment 2 data alone $(\mathrm{p}<.02$ and $<.05$ ).

In order to provide a basis for interpreting the attention-control utterances, a judge characterized each utterance in two ways: first, according to the kind of content that had immediately preceded it, and second, according to the judge's intuitive impression of what the $\mathrm{S}$ was trying to accomplish by controlling his attention at that point. The first classification revealed that during the manual puzzle and logic problem conditions, $60 \%$ of attention-control utterances followed actual problem-solving steps, $23 \%$ followed task-related comments irrelevant to solving it or unrelated comments, $14 \%$ followed pauses, and 3\% followed evaluative utterances. In the revery and hypnagogic conditions, $32 \%$ of the utterances followed pauses, $32 \%$ followed segments not apparently related to any problem the $\mathrm{S}$ was engaged in solving, $18 \%$ followed comments related to problems the Ss had imported into these conditions to solve, and another $18 \%$ followed actual problem-solving steps. On the basis of the more subjective classification, the judges found nearly half
(46\%) at points where the S had apparently bogged down during problem solving, $32 \%$ after a mindwandering episode, $16 \%$ after successful completion of a problem-solving step when the $S$ seemed to be trying to figure out what to do next, and 5\% following a discovery that the $\mathrm{S}$ was trying to apply to a solution. These percentages were similar for all experimental conditions, except that in the manual puzzle condition, Ss seemed to be reorienting following a successful step more often (32\%) than in the other conditions (7\%), and returning from mindwandering less often (16\% vs $42 \%)$.

\section{DISCUSSION}

The results clearly confirm the principal hypothesis that operant activity contains more utterances in which the $S$ evaluates his previous thoughts and in which he reorients his attention to some particular focus, presumably thereby overriding the forces that in respondent thought produce shifts from one kind of content to another. The very few Ss who made more operant $u$ tterances under the nonoperant treatments were typically working on problems they had imported.

The unpredicted finding that Ss emitted more evaluative utterances in the manual puzzle than in the logic problem conditions suggests that, as one might expect, the nature of the operant task affects the number of evaluative (and probably attention-control) utterances.

The data suggest that attention control becomes especially important at the end of an integrated segment of thought, for instance when the S's latest manipulation of a puzzle succeeded or failed or bogged down. Thus, attention control seems to reorient the $\mathrm{S}$ to his problem and lays the groundwork for launching a further integrated response sequence to solve it.

There are several implications of the theoretical position taken here. First, it suggests the probable value of investigating (a) the functional role of the operant elements of thought, (b) the conditions that affect their development, (c) the response and ability factors that determine their occurrence during particular problem-solving episodes, (d) the relation of task structures to their occurrence, and (e) their role in creating and responding to mental fatigue. Second, this view suggests a conceptualization of cases in which fragmentation or drift of thought becomes problematic, as in schizophrenics and impulsive children. Buss and Lang (1965), for instance, noted informal observations that schizophrenics make fewer self-guiding comments than do nonschizophrenics. The value of training impulsive children and

Table 2

Comparisons Among Pairs of Conditions in Numbers of Evaluative and Attention-Control Utterances, Experiments 1 and 2

\begin{tabular}{|c|c|c|c|c|c|}
\hline \multirow{2}{*}{$\begin{array}{c}\text { Condi- } \\
\text { tion }\end{array}$} & \multirow[b]{2}{*}{$\mathrm{R}^{*}$} & \multicolumn{4}{|c|}{ Condition } \\
\hline & & MP & LP & $\operatorname{Re}$ & Hy \\
\hline \multirow{2}{*}{ MP } & Eval & - & .04 & .001 & .001 \\
\hline & At-C & - & n.s. & .01 & .001 \\
\hline \multirow{2}{*}{ LP } & Eval & $15 / 20$ & - & .001 & .001 \\
\hline & At-C & $9 / 21$ & - & .001 & .001 \\
\hline \multirow{2}{*}{$\operatorname{Re}$} & Eval & $23 / 25$ & $18 / 21$ & - & n.s. \\
\hline & At-C & $14 / 17$ & $22 / 24$ & - & n.s. \\
\hline \multirow{2}{*}{ Hy } & Eval & $22 / 23$ & $19 / 20$ & $8 / 12$ & - \\
\hline & At-C & $16 / 18$ & $23 / 26$ & $7 / 13$ & - \\
\hline
\end{tabular}

${ }^{*} R=$ response. Note-Above the diagonal: significance levels of nondirectional sign tests. Below the diagonal: proportion of Ss for whom the number of utterances in the row condition was less than in the column condition, omitting cases where they were equal. 
test-anxiou s college students to talk to them selves constructively has been demonstrated (Meichenbaum, 1971, 1974, in press; Wine, 1971). The theory of operant elements and the attendant theory of response integration (Klinger, 1971) may help to account for and extend these results. Third, the view taken here suggests an approach to the general study of self-regulation.

\section{REFERENCES}

Buss, A. H., \& Lang, P. J. Psychological deficit in schizophrenia: I. Affect, reinforcement, and concept attainment. Journal of Abnormal Psychology, 1965, 70, 2-24.

DeGroot, A. Thought and choice in chess. The Hague: Mouton, 1965.

Klinger, E. Structure and functions of fantasy. New York: Wiley, 1971 .

Meichenbaum, D. H. Training impulsive children to talk to them selves: A means of developing self-control. Journal of Abnormal Psychology, 1971, 77, 115-126.

Meichenbaum, D. H., \& Cameron, R. Clinical potential of modifying what clients say to themselves. Psychotherapy,
1974, in press.

Newell, A. \& Simon, H. A. Human problem solving. Englewood Cliffs, New Jersey: Prentice-Hall, 1972.

Wine, J. Test anxiety and direction of attention. Psychological Bulletin, 1971, 76, 92-104.

\section{NOTE}

1. Ideally, the conditions would, of course, have been counterbalanced. However, the data of Experiment 1 are a portion of an unfinished counterbalanced design originally begun for another purpose, a content analy sis of segmental structure. described elsewhere (Klinger, 1971). It became apparent much later that the data could be used to test the newly formulated hypotheses concerning operant elements. Experiment 2 was performed subsequently to inquire whether the earlier results could be attributed to order. Since the effects were replicated in essentials, examination of still other orders seemed highly unlikely to discover any thing further.

(Received for publication April 9, 1974.)

\title{
Operant performance in inbred mice*
}

\author{
RICHARD L. SPROTT* and JAMES P. SYMONS \\ Jackson Laboratory, Bar Harbor, Maine 04609
}

\begin{abstract}
The procedures described in this report are standard operant procedures, which have been used successfully to condition mice to barpress for a food reward on a variety of schedules of reinforcement. The schedules of reinforcement include continuous reinforcement, nine fixed ratio values, and six fixed interval values. Mice of five genotypes have been exposed to some or all of these schedules. Performance was typical of that observed in other organisms, and satiation was not a problem in sessions lasting from 2 to $3^{1 / 2} \mathrm{~h}$. This experiment clearly demonstrated that barpress performance can be obtained with inbred mice as readily as with other organisms.
\end{abstract}

Recent advances in behavior-genetic research using

*This research was supported by an allocation from General Research Support Grant RR 05545 from the Division of Research Resources to the Jackson Laboratory and by Institutional Funds of the Jackson Laboratory. The Jackson Laboratory is fully accredited by the American Association for Accreditation of Laboratory Animal Care. genetically controlled populations of mice have resulted in a considerable increase in the sophistication of behavior-genetic techniques. As a consequence, inbred mice and their derivatives are being used with increased frequency in other biological disciplines when behavioral questions arise. Superior genetically controlled mice 